\title{
Tree-ring analysis of teak (Tectona grandis L.F.) in central India and its relationship with rainfall and moisture index
}

\author{
Somaru Ram*, H P Borgaonkar and A B Sikder \\ Indian Institute of Tropical Meteorology, Pune 411 008, India. \\ *e-mail:somaru@tropmet.res.in
}

\begin{abstract}
Tree-ring-width index chronologies of teak (Tectona grandis L.F.) from three sites in central India have been studied for their dendroclimatic potential. The existence of good correlation among the three site chronologies indicates the influence of common forcing factor to the tree growth of the region. Tree growth and climate relationship based on correlation analysis revealed the important contribution of moisture index and rainfall rather than the direct influence of the temperature on tree growth during different seasons. Significant positive relationship of moisture index and rainfall during the monsoon months as well as on the annual scale with tree-ring width variations over the region indicates the important role of moisture availability at the root zone. The results suggest that the teak tree-ring chronologies can be used as high resolution proxy for past precipitation and moisture level in the environment.
\end{abstract}

\section{Introduction}

Information on climate variability during the recent past about 1000 years, which is the period of man's greatest impact on the planet, is vital to understand the various internal and anthropogenic influences on the climate and thereby make reliable future projections. In this time frame, the tree-rings, with their inter-annual resolution, are globally recognized to be among the best archives of past climate.

In India, conifers (viz., Pinus, Picea, Cedrus and Abies) tree-ring based regional climate reconstructions over western Himalaya (Hughes 1992; Borgaonkar et al 1994, 1996; Pant et al 1998; Yadav et al 1999, 2004) gave pre-monsoon and summer climate variability of the past 300 years. However, little attention is given to dendroclimatic studies over the central and peninsular Indian region which is highly influenced by the tropical monsoon system. In tropical regions of south and southeast Asia, a number of groups have been working to establish high resolution tree-ring data network to understand monsoon variability and related global parameters (e.g., ENSO) in the recent past. In this context, teak (Tectona grandis) from Indonesia, Thailand, Java, India have been demonstrated as a potential source for high resolution spatial reconstruction of climate (D'Arrigo et al 1994; Pumijumnong et al 1995; Murphy and Whetton 1989; Pant and Borgaonkar 1983; Bhattacharayya et al 1992; Jacoby and D'Arrigo 1990). These studies indicate high potential of Tectona grandis in reconstruction of regional climate (monsoon) related parameters (e.g., rainfall, drought frequencies and intensities, ENSO/El Niño, etc.). However, a large temporal and spatial network of tree-ring chronologies in this region is needed to understand past variations of rainfall and related parameters.

In this paper, we present analysis of tree-ring width index chronologies of teak (Tectona grandis) from three sites of central India namely Bori, Sajpur from Madhya Pradesh and Edugurapalli from Andhra Pradesh to evaluate their dendroclimatic potential in relation to rainfall, temperature and moisture variation over the region.

Keywords. Central India; teak (Tectona grandis); tree-ring; moisture index; temperature; precipitation. 


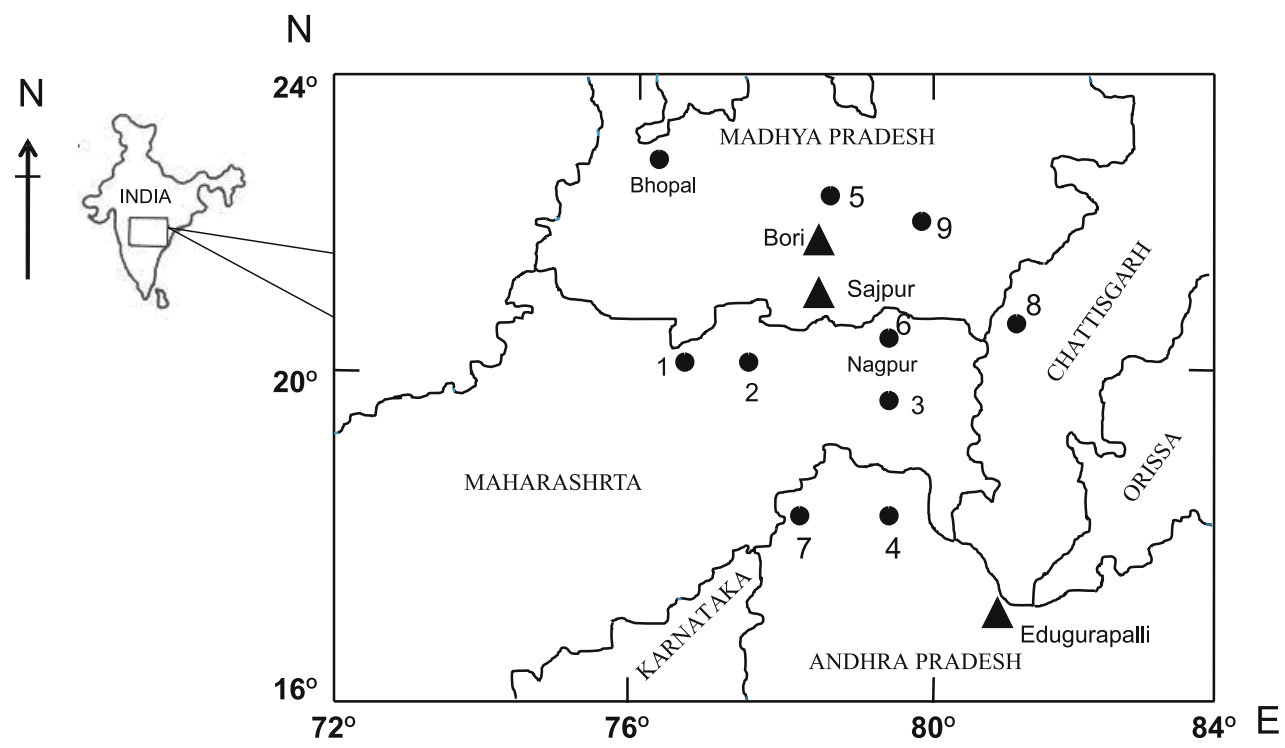

Figure 1. Tree-ring site locations with meteorological stations: $\boldsymbol{\Delta}$ Tree-ring sites; - Meteorological stations (1: Akola, 2: Amraoti; 3: Chandrapur; 4: Hanumakonda; 5: Hoshangabad; 6: Nagpur; 7: Nizamabad; 8: Raipur; 9: Seoni).

\section{Tree-ring data}

The tree-ring core samples of teak were collected from Bori, and Sajpur forest area of eastern Madhya Pradesh and Edugurapalli of northern Andhra Pradesh during 2000 and 2002 (figure 1). The sites are located in the natural forest areas where, human influences are minimal. Two treering cores per tree were taken using increment borer at the breast height from stem with the aim to extract all the growth-rings present in the tree. All cores were processed in the laboratory using standard dendrochronological techniques (Fritts 1976). Skeleton plot method was used to assign exact year of growth to each and every ring (Stokes and Smiley 1968). Ring-widths of all samples were measured under the high magnification stereo-zoom microscope system with an accuracy of $10^{-3} \mathrm{~cm}$. The accuracy in crossdating and possible measurement errors were identified using the data quality control programme COFECHA (Holmes 1983), which identifies treering data segment-wise that may have either dating or measurement errors. Samples having dating problems were re-examined and errors were corrected. The computer program ARSTAN (Holmes et al 1986; Cook et al 1990) was used to standardize the tree-ring series. The options, viz., negative exponential or cubic spline fit of wave length equal to $35 \%$ of $N$ where, $N$ is the number of data points in individual tree-ring series were used to detrend the series. Indices of each series were derived by dividing the actual ring-width value by the corresponding smooth value for each year. The autocorrelation patterns in the series were removed using an auto-regressive model. The site ring width index chronologies were prepared by averaging all the tree-ring index series over the individual site. Three site tree-ring width index series are shown in figure 2 along with sample size variation.

The statistical performance of these ring width index chronologies is given in table 1 . The tree-ring chronologies having high values of mean sensitivity, standard deviation, mean correlation (common variance), signal-to-noise ratio (SNR) and low persistence (auto-correlation), are supposed to be suitable for use in climate reconstruction (Fritts 1976). All the ring width series show high autocorrelation. The autocorrelation is the correlation or linkage of each value with the immediately preceding value in the series. The large value of autocorrelation and low value of mean sensitivity indicate the presence of more low frequency variance in the series. When the case is reverse, the high frequency variance in the series is more. The high frequency variance is of more interest for dendroclimatic studies. Autoregressive modeling removes an autocorrelation structure in the series and enhances the common signal. An autoregressive (AR) modeling has been selected based on the pooled autoregressive procedure in the program ARSTAN (Holmes et al 1986). The order of the AR model is based on Akaike Information Criterion (AIC).

Moderately high values of standard deviation, mean sensitivity and common variance (mean correlation among all the tree samples) in table 1 indicate the high dendroclimatic potential of these three chronologies. The mean sensitivity (MS), which is the measure of the relative difference in the width from one ring to the next, is moderately high 

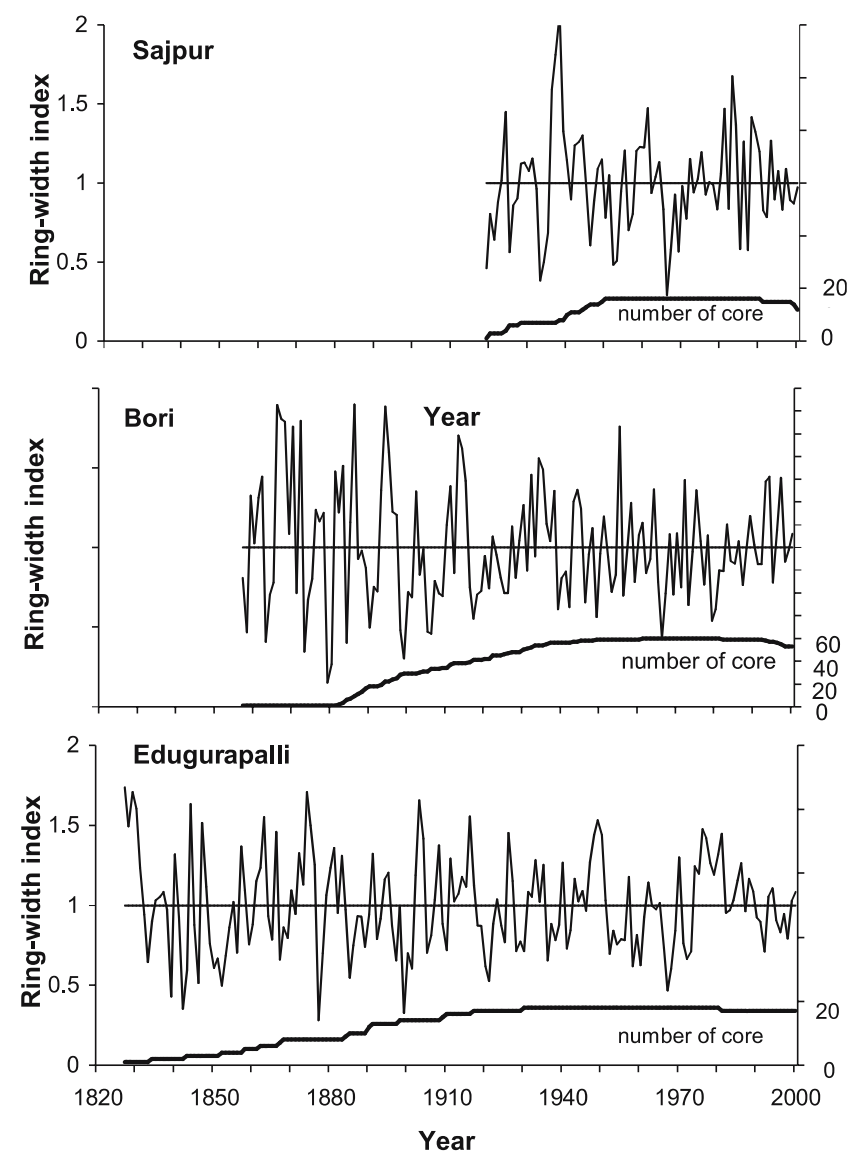

Figure 2. Three tree-ring chronologies from central India with number of tree cores used.

for all the three chronologies. The theoretical range of mean sensitivity is zero to two. If there is no difference in the adjacent ring widths, the MS is zero and it is two when zero value occurs next to nonzero value. Mean correlation coefficients defined in the table are the mean of correlation coefficients of all possible pairwise combinations of ring series in the common interval. This is also termed as mean correlation between the trees (Fritts 1976). SNR $>1$ indicates the more common useful signal than the residual noise. The value of SNR is moderately high for all the three chronologies with highest SNR of Bori chronology.

Agreement with population chronology indicates the usefulness of the chronologies in past climate reconstruction. Total variance in the chronology is composed of common signal and residual noise. When common signal is expressed as a fraction of total chronology variance, it is termed as agreement with population chronology or Expressed Population Signal (EPS) (Wigely et al 1984). EPS decides the agreement of sample chronology with the population chronology. Wigley et al (1984) suggest that chronologies with EPS $\geq 0.85$ can be accepted as reliable chronology for dendroclimatic reconstructions. Table 1 shows the values of different statistics of the chronologies after the auto-regression (residual version). The values inside the brackets in table 1 are without autoregressive modeling. It is observed that after the auto-regression the overall statistical performance of the tree-ring chronologies has improved. Therefore we use the residual version of the three tree-ring chronologies for further dendroclimatic analysis henceforth.

\section{Climate data}

Monthly rainfall and temperature data of nine stations (viz., Akola, Amraoti, Chandrapur, Hanumkonda, Hoshangabad, Nagpur, Nizamabad, Raipur and Seoni) around the tree-ring sites for the period 1901-2000 were used in the dendroclimatic analysis. The stations cover the region between $18^{\circ} \mathrm{N}$ to $23^{\circ} \mathrm{N}$ and $77^{\circ} \mathrm{E}$ to $83^{\circ} \mathrm{E}$ (figure 1 ). As the data are homogeneous and continuous for a century period, average monthly datasets of rainfall and temperature have been prepared for the region by merging respective datasets of the nine stations so that potentially more reliable data can be used in tree growth climate relationship analysis. This regional data show similar pattern of monthly variation in rainfall and temperature as the pattern of individual stations (figure 3). May is the hottest month and July receives the highest rainfall during the year. Temperature reaches its minimum value in the month of December. Mean temperature is above $20^{\circ} \mathrm{C}$ throughout the year with May and April being the warmest months.

\section{Tree-ring growth climate relationship}

The tree-ring sites considered in this study are under the influence of the Indian monsoon region. More than $75 \%$ of the total annual rainfall is received during the monsoon months (June-September) (figure 3). Pre-monsoon season (March-May) is normally warm and dry. While a small amount of rainfall during these months is conducive for the new cell formation, warm (hot) and dry pre-monsoon season creates noticeable moisture scarcity which directly affects the tree growth. The monsoon as well as the total annual rainfall indicates significant positive relationship with tree-ring width variations (Bhattacharyya et al 1992; Sikder 2003). However, the general observations on relationship between the teak ring width variations and climatic parameters reveal that the low growth years (narrow ring) are significantly associated with deficient rainfall (drought condition) in most of the cases. Normal or above 
Table 1. General statistics of tree-ring chronologies (the values inside the brackets are without autoregressive modeling).

\begin{tabular}{|c|c|c|c|}
\hline & Sajpur & Bori & Edugurapalli \\
\hline Period & $1919-2000$ & $1857-2001$ & $1827-2000$ \\
\hline Years & 82 & 145 & 174 \\
\hline No. of cores (trees) & $6(12)$ & $60(37)$ & $18(10)$ \\
\hline Standard deviation & $0.28(0.26)$ & $0.35(0.36)$ & $0.27(0.24)$ \\
\hline Lag-1 autocorrelation & $-0.05(0.45)$ & $-0.09(0.48)$ & $-0.04(0.58)$ \\
\hline Mean sensitivity & $0.34(0.28)$ & $0.43(0.35)$ & $0.31(0.28)$ \\
\hline \multicolumn{4}{|l|}{ Common Period Analysis } \\
\hline Period & $1951-1998$ & 1934-2001 & $1911-2000$ \\
\hline No. of years & 48 & 68 & 90 \\
\hline No. of cores (trees) & $15(12)$ & $47(29)$ & $15(10)$ \\
\hline Common variance & $0.31(0.28)$ & $0.32(0.27)$ & $0.31(0.25)$ \\
\hline Signal-to-noise ratio & $5.4(4.7)$ & $13.8(10.7)$ & $4.6(3.3)$ \\
\hline Agreement with population & $0.85(0.83)$ & $0.93(0.89)$ & $0.82(0.79)$ \\
\hline
\end{tabular}

normal rainfall is not reflected as a significant higher growth. This is mainly because of moisture available at the root zone of the tree. When the moisture availability reaches a certain threshold value, the tree does not respond to the additional moisture, whereas, less moisture at root zone creates an adverse condition for tree growth. In view of this, we examine here the role of moisture in tree growth process. For this purpose monthly moisture index (MI) values over the region were calculated using Thornthwaite (1948) method. MI is given by $\mathrm{MI}=P$-PET, where $P$ is the monthly rainfall and PET is potential evapotranspiration determined for each month using an empirical formula developed by Thornthwaite (1948) as follows:

$$
\mathrm{PET}=16 L(10 T / I)^{a},
$$

where $\mathrm{PET}=$ potential evapotranspiration in $\mathrm{mm} /$ month, $T=$ monthly mean temperature in ${ }^{\circ} \mathrm{C}, L=$ adjustment for day length which is dependent on the latitude of the place, $I=$ the total of 12 monthly values of the heat indices $(I)$ and determined from $I=(T / 5)^{1.514}$.

$I$ and $\mathbf{a}$ are related by the following equation

$\mathbf{a}=0.49+0.0179 I-0.0000771 I^{2}+0.000000675 I^{3}$.

The moisture index which is a function of rainfall and temperature was calculated for nine stations individually and averaged over the region from January to December. Correlation analysis for each tree-ring site was carried out using the seasonal temperature, precipitation and moisture

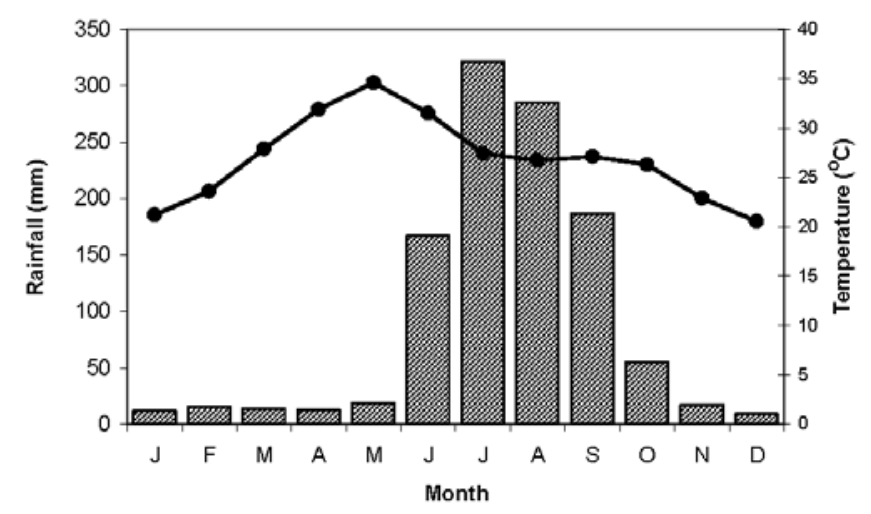

Figure 3. Average monthly variation of rainfall (bars) and mean surface temperature (thick line) over central India based on the data period 1901-2000.

index data derived from the monthly data of nine meteorological stations as mentioned in the above paragraphs for the period 1901-2000. It was observed that correlation analysis on a monthly scale did not give significant coherent pattern of relationship between the three tree-ring index chronologies and temperature, rainfall and moisture index series. However, seasonal data, particularly moisture index (MI) during monsoon season (JJAS) and annual scale indicate significant positive relationship with all the three tree-ring index chronologies. Table 2 gives the correlation coefficient values of three tree-ring index chronologies with seven seasons, viz., previous monsoon (-JJAS) and post-monsoon (-ON), current winter (DJF), pre-monsoon (MAM), monsoon (JJAS), post-monsoon $(\mathrm{ON})$ and annual series of temperature, rainfall and moisture index.

Though the temperature is an important parameter in photosynthesis, the correlation analysis of 
Table 2. Correlation analysis of three tree-ring index chronologies from central India with regional temperature (TEM), rainfall (RF) and moisture index (MI).

\begin{tabular}{|c|c|c|c|c|c|c|c|c|}
\hline $\begin{array}{l}\text { TR index } \\
\text { chronology }\end{array}$ & & -JJAS & $-\mathrm{ON}$ & DJF & MAM & JJAS & $\mathrm{ON}$ & Annual \\
\hline & TEM & -0.02 & -0.04 & -0.04 & -0.01 & -0.15 & -0.20 & $-0.22^{*}$ \\
\hline Sajpur & $\mathrm{RF}$ & 0.06 & 0.17 & 0.04 & 0.03 & $0.28^{*}$ & $0.23^{*}$ & $0.33^{*}$ \\
\hline$(1919-2000)$ & MI & 0.05 & 0.18 & 0.06 & 0.02 & $0.29^{*}$ & $0.27^{*}$ & $0.35^{*}$ \\
\hline & TEM & -0.14 & -0.17 & -0.06 & -0.13 & -0.17 & $-0.18^{*}$ & $-0.28^{*}$ \\
\hline Bori & $\mathrm{RF}$ & 0.16 & 0.11 & -0.05 & -0.08 & 0.17 & 0.04 & 0.12 \\
\hline$(1901-2000)$ & MI & 0.06 & $0.20^{*}$ & -0.05 & 0.11 & $0.20^{*}$ & 0.11 & $0.23^{*}$ \\
\hline & TEM & -0.16 & -0.07 & -0.08 & -0.14 & -0.13 & 0.11 & -0.12 \\
\hline Edugurapalli & $\mathrm{RF}$ & 0.16 & $0.21^{*}$ & 0.01 & 0.14 & $0.24^{*}$ & 0.05 & $0.25^{*}$ \\
\hline$(1901-2000)$ & MI & $0.20^{*}$ & 0.12 & 0.02 & 0.17 & $0.26^{*}$ & -0.05 & $0.27^{*}$ \\
\hline
\end{tabular}

Note: Figures with $*$ indicate significant values at $5 \%$ level.

table 2 indicates the least effect of direct influence of temperature on tree-ring variations. In general, the seasonal temperature shows non-significant negative relationship with all the three tree-ring chronologies. In case of Sajpur and Bori it gives significant negative relationship with annual temperature. Sajpur and Bori tree-ring sites are located on the slope of the hilly forest and close to each other as compared to Edugurapalli which is the plain forest site. A large amount of water received from the monsoon rainfall is drained down due to topography of Sajpur and Bori sites resulted in the moisture stress situation at the root zone which affects the normal growth of the tree. Higher temperature always accelerates evaporation and evapotranspiration which creates a severe moisture stress condition causing the below normal growth (narrow rings). Therefore, overall annual temperature gives negative relationship with tree growth. In case of the Edugurapalli site, the amount of run-off water is comparatively less because of its flat land surface. Sufficient moisture is available at root zone for longer periods even though the temperature is high. Hence, the significant effect of temperature on tree growth is not observed on the Edugurapalli site.

The significant positive relationship of monsoon and annual rainfall and moisture index with the tree growth observed over the three sites (table 2) indicates an important role of rainfall and moisture in tree-ring variations. The amount of water received during monsoon months (JJAS) is highest which moderates the temperature during these months and accelerates the photosynthesis. As this is the peak growing season of teak (Chowdhury 1964), monsoon rainfall shows significant positive relationship with tree-ring variations. Tree growth also indicates significant positive relationship with the annual rainfall.

As discussed above, the moisture availability at the root zone is also an important parameter
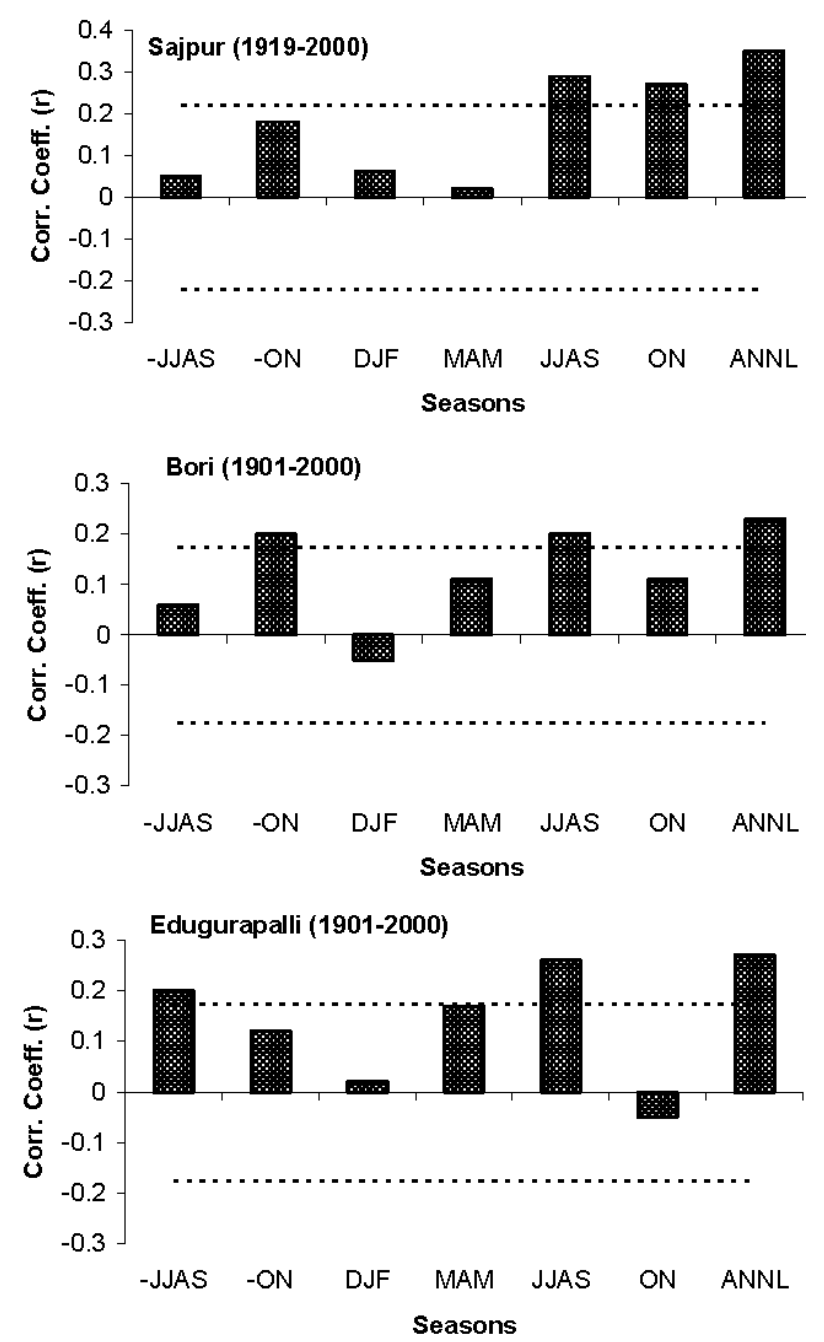

Figure 4. Correlation between seasonal moisture index (MI) and tree-ring index chronologies from central India. Dashed lines indicate the $95 \%$ of significant level.

in dendroclimatic analysis. Moisture index during monsoon and annual seasons shows significant positive relationship (table 2). In case of Bori, monsoon as well as annual rainfall is positively 

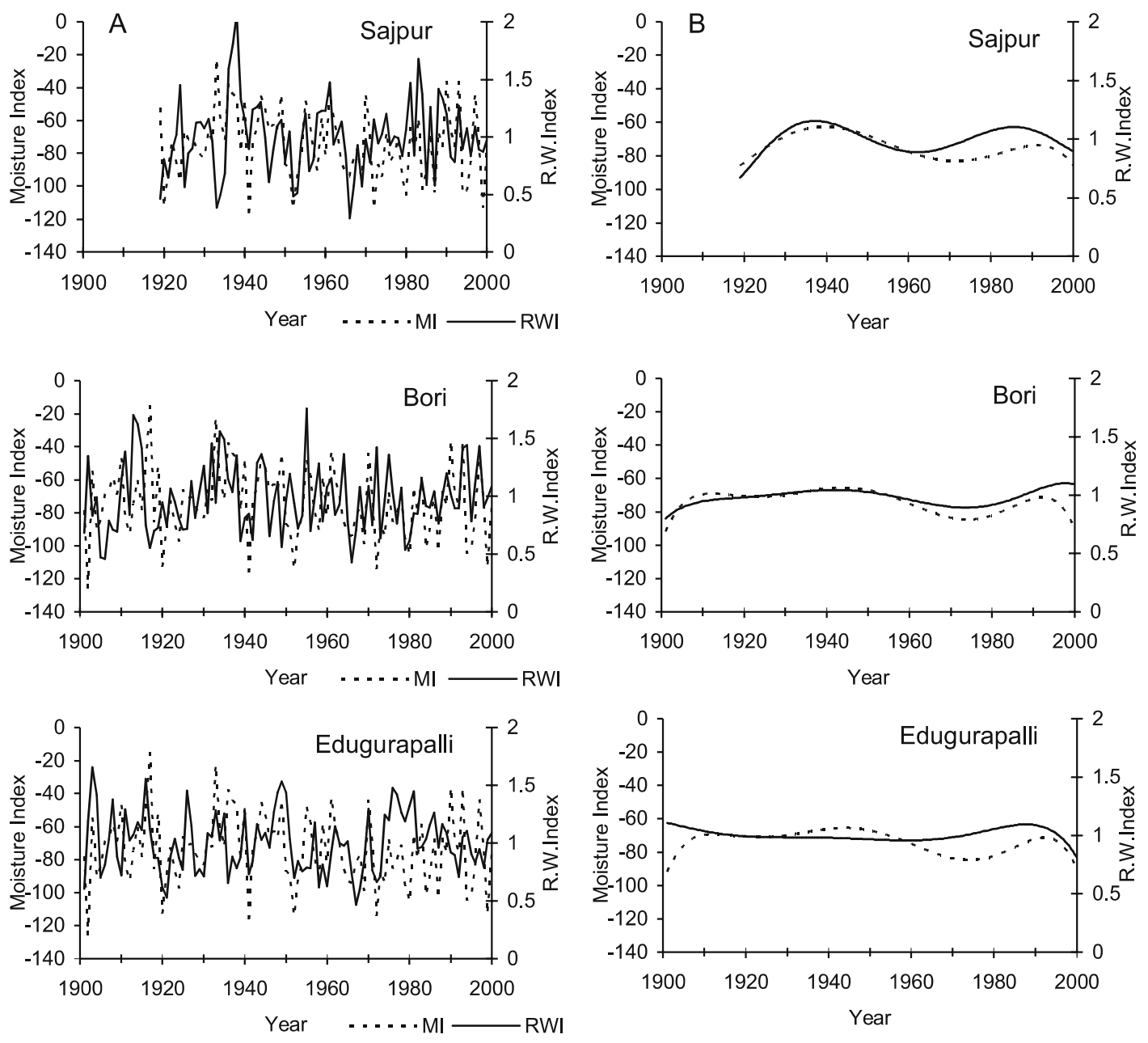

Figure 5. (A) Variations in tree-ring width index (RWI) chronologies of three different sites along with the annual variations in moisture index (MI). (B) Low-frequency variations in RWI and MI obtained with 6th degree polynomial.

correlated but not significant, whereas moisture index gives significant positive relationship with tree-ring width series over all the three sites. Figure 4 indicates an overall pattern of the relationship between the moisture index and three tree-ring width index chronologies for different seasons. The overall annual moisture condition is important in tree growth climate relationship. Moisture during the previous year's monsoon and post-monsoon season also contributes to the tree growth variation as carry-over effect (Pant and Borgaonkar 1983; Bhattacharyya et al 1992). Treering analysis of White Spruce from southwest Manitoba, Canada (Chhin et al 2004) indicates the significant association between tree growth and May-July moisture index based on Thornthwaite formula. They further indicated the applicability of such tree-ring chronologies to identify the moisture induced drought conditions. Figure 5 indicates the time series of three tree-ring width index chronologies along with the annual moisture index. The low frequency variations are obtained by fitting 6 th degree polynomial. The low frequency variations of moisture index and tree growth show very similar patterns. This may be due to the carry-over effect of moisture at the root zone. Higher rainfall during any particular year helps in maintaining the normal growth of the tree for the next two-three years even though the rainfall during these years could be less. The reverse process is also true when very less rainfall during any particular year creates moisture stress condition at root zone which may continue in the next one-two years resulting in below normal tree growth in successive years. Figure 6 shows the scattered plots of ring-width versus moisture index for three different sites with linear regression lines fitted to the relationship. As discussed earlier, the serial correlation between ring width and annual moisture index is positive and significant at $5 \%$ level for all the three sites. Figure 6 shows the increasing trend for all the three sites, but trends are barely visualized at Bori and Edugurapalli. Over the Sajpur region trend is more clear. Though, the increased tree growth in most of 

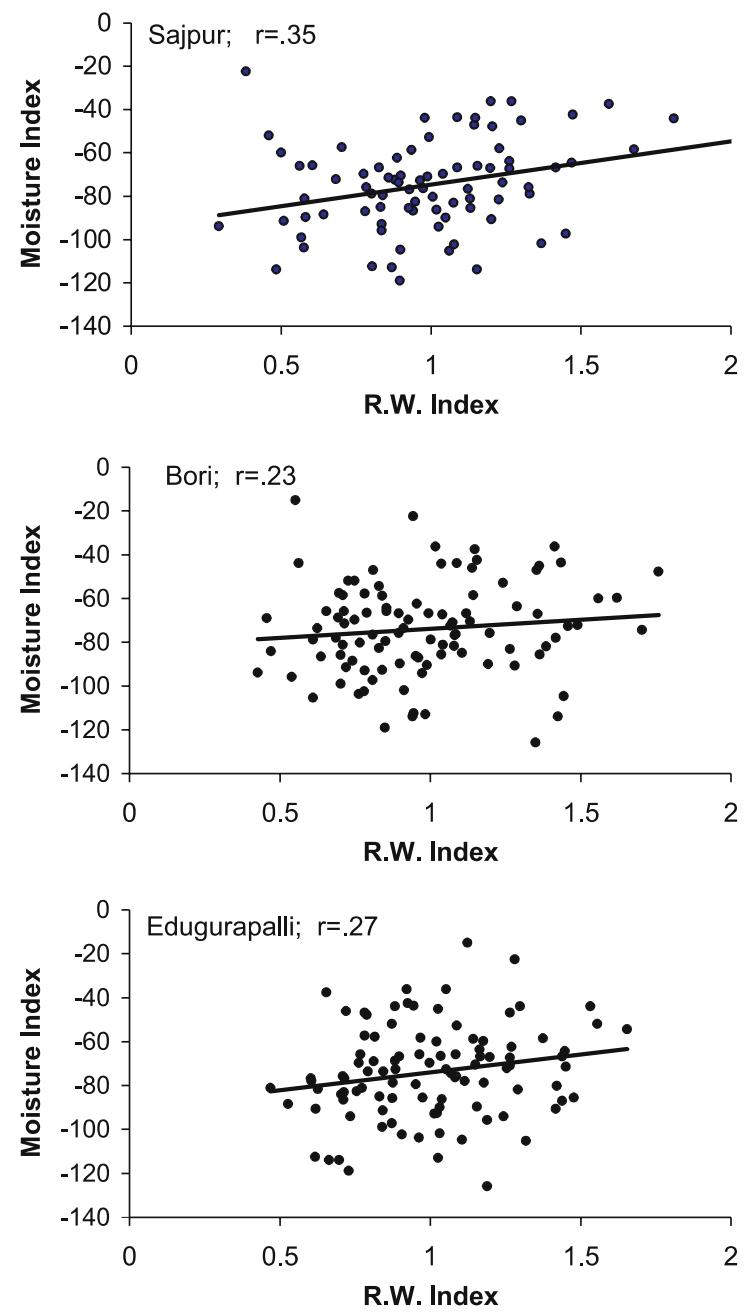

Figure 6. Scattered plots of ring width index series from three different sites with annual moisture index of the region.

the years has been found to be well associated with higher moisture index of the region, some years are out of phase due to the limiting effect of other site specific environmental factors such as the position of the trees, gravity stress, competition among the trees and a variety of other metabolic parameters (Ramesh et al 1989). Such local parameters may be more sensitive over the Bori and Edugurapalli resulting in the less increasing trend compared to the Sajpur site.

\section{Discussion and conclusions}

Teak is a tropical species and found over the entire monsoon belt of south and southeast Asian region. Dendroclimatological studies of teak from India, Myammar, Thailand, Indonesia (Pant and Borgaonkar 1983; Bhattacharyya et al 1992; Murphy and Whetton 1989; Pumijumnong et al 1995; Jacoby and D'Arrigo 1990; D'Arrigo et al 1994) suggested its suitability to understand the past vagaries of monsoon. Ramesh et al (1989) reported the strong association between the variation of stable isotopic ratio of hydrogen $(\delta D)$ in teak and the amount of rainfall to demonstrate its applicability for reconstruction of past climate. Shah et al (2007) presented summer rainfall reconstruction from central India based on the teak tree-ring data. Our analyses also indicate significant relationship of teak tree growth with monsoon related parameters. Significant positive response of teak tree-ring chronologies with monsoon and annual rainfall as well as moisture index observed in our analysis is mainly due to the moisture availability during the peak growing season of teak (May-September). It was also observed that Bori chronology could not capture the monsoon and annual rainfall signal as observed in the other two chronologies.

The relationship of tree-ring variations with climate is based on regional rainfall, temperature and moisture data prepared from the individual data of nine stations. Sajpur and Bori sites are closer compared to the Edugurapalli site which is about $500 \mathrm{~km}$ south to these two sites. Statistical performance indicates the high dendroclimatic potential of these tree-ring chronologies. Important finding of the correlation analysis is the statistically significant relationship of all the three chronologies with moisture index in spite of the distant location of Edugurapalli site. Such coherent regional climate signal though not sufficient to climate reconstruction, indicates the important role of moisture index, monsoonal rainfall in tree growth process. In teak, local climate effect is more prominent than the regional or global signals. Bhattacharyya et al (1992) demonstrated the very strong relationship between teak tree-ring chronology from Dahanu (Maharashtra, central India) and local annual rainfall of the same place. In detrending process, there is always a possibility that the part of useful signal (climate) may be lost with non-climatic signals. One possible way to improve the strength of climate signal is, more number of tree samples from wide areas to be included in the analysis.

In this study, regional moisture index has been used to understand the exact dendroclimatic relationship. The monsoon and annual moisture indices give significant positive response to tree growth over all the three sites. During monsoon season sufficient moisture is available at root zone for longer time period even though the temperature is high. Direct effect of temperature is suppressed due to the monsoon rainfall. Hence, the effect of temperature change on tree growth is not visible in the analysis. However, the moisture index which is the function of temperature and precipitation has been shown to be the more 
realistic parameter in tree growth climate relationship. D'Arrigo et al (2006) reconstructed moisture index (Palmer Drought Severity Index, PDSI) for Java, Indonesia from tree-ring that reports monsoon drought for last two centuries. The Indonesian teak chronologies are drought sensitive and in opposite phase to Indian monsoon. They indicated the strong association of tree-ring variations with moisture index during Indonesian monsoon (ON).

This study gives important information about tree-ring analysis of teak from central India and relationship governing the growth and their dendroclimatic response. The study can be extended with wide network of teak tree-ring chronologies and large number of meteorological stations, and taking into consideration the geomorphologic and other evidences which may provide a better database to reconcile tree growth/climate relationships in a longer timescale from central Indian region. This will help to look at the exact role of moisture and rainfall in tree growth process and their relationship with monsoon related regional phenomena and global parameters such as ENSO/El Niño, etc. Such extended spatio-temporal tree-ring data network of teak will be useful as high resolution proxy to estimate the past rainfall and moisture environment and drought frequencies.

\section{Acknowledgements}

The authors are thankful to Prof. B N Goswami, Director, IITM, Pune, and Dr. N Singh, Head, C \& H Division, IITM, Pune for the encouragement while carrying out this work. We are grateful to officials of the Forest Department of Madhya Pradesh and Andhra Pradesh for their help during the tree ring sample collection. We are also thankful to India Meteorological Department for providing basic meteorological data. The tree-ring data collection from central India was carried out under Project No. 9/1(5)/2000 II, sponsored by the Indian Space Research Organization-Geosphere Biosphere Programme (ISRO-GBP).

\section{References}

Bhattacharyya A, Yadav R R, Borgaonkar H P and Pant G B 1992 Growth-ring analysis of Indian Tropical trees; Dendroclimatic potential; Curr. Sci. 62 736-741.

Borgaonkar H P, Pant G B and Rupa Kumar K 1994 Dendroclimatic Reconstruction of Summer Precipitation at Srinagar, Kashmir, India since the late 18th Century; Holocene 4 299-306.

Borgaonkar H P, Pant G B and Rupa Kumar K 1996 Ring-width variations in Cedrus deodara and its Climate Response Over the Western Himalaya; Int. J. Climatol. 16 1409-1422.
Chhin S, Wang G G and Tardif J 2004 Dendroclimatic analysis of white spruce at its southern limit of distribution in the spruce wood provincial park, Manitoba, Canada; Tree-ring Res. 60(1) 31-34.

Chowdhury K A 1964 Growth rings in tropical trees and taxonomy; J. Ind. Bot. Soc. 43 334-342.

Cook E R, Briffa K R, Shiyatov S and Mazepa V 1990 Tree-ring standardisation and growth-trend estimation; In: Methods of Dendrochronology (eds) Cook E R and Kairiukstis L A (Dordrecht, The Netherlands: Kluwer Academic Publishers) 104-123.

D' Arrigo R D, Jacoby G C and Krusic P J 1994 Progress in dendroclimatic studies in Indonesia; Terr. Atmos. Oceanogr. Sci. 5 349-363.

D' Arrigo R D, Wilson R, Palmer J, Krusic P J and Curtis A 2006 A global data set of PDSI for 1870-2002: Relationship with soil moisture and effects of surface warming; Geophys. Res. Lett. 33 L04709, doi: 10.1029/2005GL025465.

Fritts H C 1976 Tree-rings and climate (London: Academic Press) pp 567.

Holmes R L 1983 A computer assisted quality control in tree-ring dating and measurement; Tree-Ring Bull. 43 69-78.

Holmes R L, Adams R K and Fritts H C 1986 Treering chronologies of western north America: California, eastern Oregon and northern Great Basin with procedure used in the chronology development work including User's Mannual for computer programs COFECHA and ARSTAN; Chronology Series-VI, Laboratory of tree-Ring Research, University of Arizona, Tucson, USA.

Hughes M K 1992 Dendroclimatic evidence from the western Himalaya; In: Climate since AD1500 (eds) Bradley R S and Jones P D, Routledge, London, 415-431.

Jacoby G C and D' Arrigo R D 1990 Teak (Tectona grandis LF) A tropical species of large scale dendroclimatic potential; Dendrochronologia 8 83-98.

Murphy J O and Whetton P H 1989 A re-analysis of treering chronology from Java; Proce. koninkl. Nederl. Akad. Wetensch. B 92 241-257.

Pant G B and Borgaonkar H P 1983 Growth rings of teak trees and regional climatology (An ecological study of Thane region); In: Environmental Management (eds) Singh L R, Singh S, Tiwari R C and Srivastava R P, Geogr. Soc. Allahabad, India, p.153-158.

Pant G B, Borgaonkar H P and Rupa Kumar K 1998 Climatic Signals from Tree-rings; A Dendroclimatic Investigation of Himalayan Spruce (Picea smithiana), Himalayan Geology 19(2) 65-73.

Pumijumnong N, Eckstein D and Sass U 1995 Tree-ring research on Tectona grandis in Northern Thailand; IAWA Journal 16(4) 385-392.

Ramesh R, Bhattacharya S K and Pant G B 1989 Climatic significance of $\delta D$ variations in a tropical tree species from India; Nature 337 149-150.

Shah S K, Bhattacharyya A and Chaudhary V 2007 Reconstruction of June-September precipitation based on tree-ring data of teak (Tectona grandis L.F.) from Hoshangabad, Madhya Pradesh, India, Dendrochronologia 25 57-64.

Sikder A B 2003 Tree-ring an indicator of past environment a case study of Tectona grandis (teak) in Bori forest, Madhya Pradesh, India, M.Sc. Thesis, University of Pune, Pune, India.

Stokes M A and Smiley T L 1968 An introduction to tree-ring dating; The University of Chicago Press, Chicago. 
Thornthwaite C W 1948 An approach toward a rational classification of climate; Geogr. Rev. $\mathbf{3 8}$ $55-94$.

Wigely T M L, Briffa K R and Jones P D 1984 On the average value of correlated time series with applications in dendroclimatology and hydrometeorolgy; J. Climate and Appl. Meteorol. 23 201-213.
Yadav R R, Park W K and Bhattacharyya A 1999 Spring temperature fluctuations in the western Himalayan region as reconstructed from tree-rings; AD1390-1987, Holocene 9 85-90.

Yadav R R, Park W K, Singh J and Dubey B 2004 Do the western Himalayas defy global warming; Geophys. Res. Lett. 31 L17201 doi: 10.1029/2004GL02020.

MS received 19 February 2007; revised 19 May 2008; accepted 28 May 2008 